\title{
Managing the CIGÉO Design: A Challenge and an Opportunity
}

\author{
Roberto Muscetti \\ International Projects Development Program, INGEROP Group, Cébazat 63118, France
}

Received: October 08, 2015 / Accepted: November 04, 2015 / Published: December 31, 2015.

\begin{abstract}
INGEROP has been working for years on the French deep geological repository's design for ANDRA, carrying out since 2012 the preliminary design, the global project management and the technical integration for the engineering of the CIGÉO project (in a 50-50 consortium with the French company TECHNIP). The article presents some particular organizational aspects that, turned out to be more challenging than foreseen in the course of our activities. Starting from the presentation of real examples, some lessons learned are derived as well as practices of interest in solving analogue issues in similar projects, with focus on its application to the management of the engineering phase of geological repositories and other' megaprojects' in different countries.
\end{abstract}

Key words: Radioactive waste, disposal, repository, geological, organization.

\section{Nomenclature}

DGR Deep geological repository

\section{Introduction}

\subsection{The Project}

CIGÉO is the French deep geological disposal project managed by ANDRA (French National Radioactive Waste Management Agency) [1]. It will serve as a repository for HLW and ILW (high-level and intermediate-level) long-lived radioactive waste generated by the country's current fleet of nuclear power plants, from operation to dismantling, as well as the vitrified waste from the reprocessing of spent nuclear fuel, taking into account the safety requirements given by the national regulator [2].

Circa 235,000 waste packages will be stored some $500 \mathrm{~m}$ below ground in an impermeable argillaceous rock formation (Callovo-Oxfordian clay), that will be able to contain radioactivity over very long periods. A general view of the facilities is given in Fig. 1.

Corresponding author: Roberto Muscetti, M.Sc.Eng., research fields: nuclear engineering and radioactive waste management.

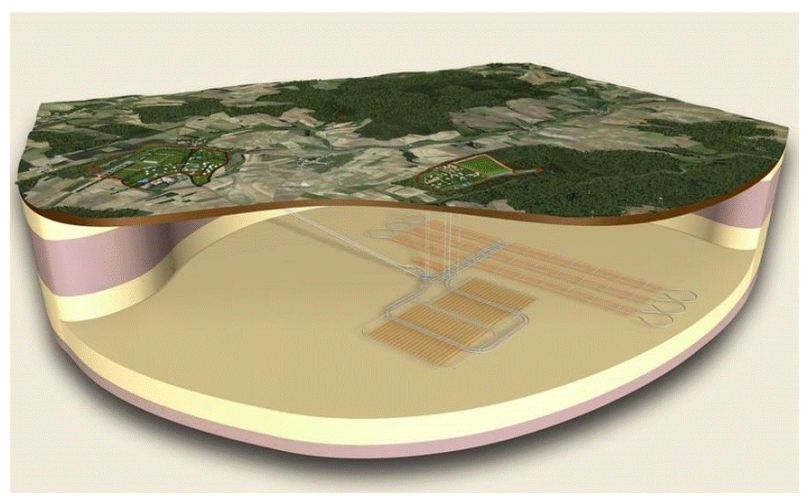

Fig. 1 A general 3D view of CIGÉO-CANDRA.

The DGR (deep geological repository) will be located in north-eastern France, and will feature several surface facilities for the management of the waste packages, connecting wells and declines to the underground structures - with more than $300 \mathrm{~km}$ of horizontal tunnels and cells to be excavated and equipped, corresponding to a volume of some 8 million cubic meters of excavated material, $40 \%$ of which will eventually be re-used to close the facility.

CIGÉO is designed to operate for more than 100 years before its definitive closure, and the different sectors housing disposal cells for HLW and ILW are planned to be put into operation by batches, which 
means that, there shall be coactivity between the nuclear operations of the completed sectors and the excavation and construction activities of new sectors in the same confined underground space.

The facility's design is expected to be flexible over time, so as to give the future generations the possibility to adapt it to new technologies and requirements, changes in waste policies, and feedback from operations and tests.

The project entered its industrial preparation phase in 2012 and operations are scheduled to begin in 2025. The next main steps in the legal process, according to a basic schedule which is still under discussion, include:

- the approval of the act on reversibility conditions of disposal by French government (in 2016);

- the submittal of the full construction license by 2018;

- from 2018 to 2020, the review of the construction license application by the competent authorities and the consultation of local communities;

- the approval of the construction license (after completion of the previous steps) in late 2020 .

\subsection{The Engineering Activities}

The French engineering group INGEROP, after being involved for years in the conceptual studies on the French deep geological repository's design for ANDRA, is carrying out since 2012 the global project management and the technical integration for the CIGÉO project.

Its activities have been carried out in the framework of a 50-50 consortium called "GAIYA" - a name coming from the Greek goddess of earth and an African word for collective endeavor-with the French company TECHNIP, and concerned, at first, the engineering for the preliminary design, concluded in early 2013, and then the management and integration of the engineering studies for the basic design phase, which is still ongoing, followed by the detail design phase (to last until mid-2017).

\section{Managing CIGÉO Engineering}

\subsection{A Glimpse of the Extent and Complexity of the Project}

The management of the engineering of the CIGÉO [3] project requires not only a sound organization and a solid control structure but also the support of topnotch expertise in several domains.

These demanding missions call for team members with multifaceted skills, having an overall, global view and capable of assuring coherence within a quite evolving environment (updates of technical requirements, governmental requirements, public opinion, etc.). Indeed, the general lack of experience on similar projects - practically it is a first of a kind, at least of similar size and momentum in Europe-makes the task even harder.

Since the end of 2013, owing to the project's proportions, the project team's everyday activities consisted largely in driving the interaction and manage the interfaces between five consortia of specialized subcontractors dealing with the engineering of subsystems and specific topics, having thus only a partial vision.

The project is intrinsically multidisciplinary, counting tenths of scientific and technical fields like geomechanics, geophysics, hydrogeology, mechanics, ventilation, filtering, handling, transports engineering, civil engineering, mechanics, radiation protection, environmental protection, human factor integration, stream and workflow analysis, architecture, landscaping, etc., a whole set of different sensibilities and approaches to bring together.

The overall progress of the design is ensured by controlled iterations, where the results of parallel activities carried out by the five consortia of subcontractors, advancing at different speeds due to very different perimeters and characteristics, are periodically verified and re-aligned to guarantee technical consistency and stay in line with the main targets in terms of construction budget and schedule (see Fig. 2 to realize the schedule's complexity). 


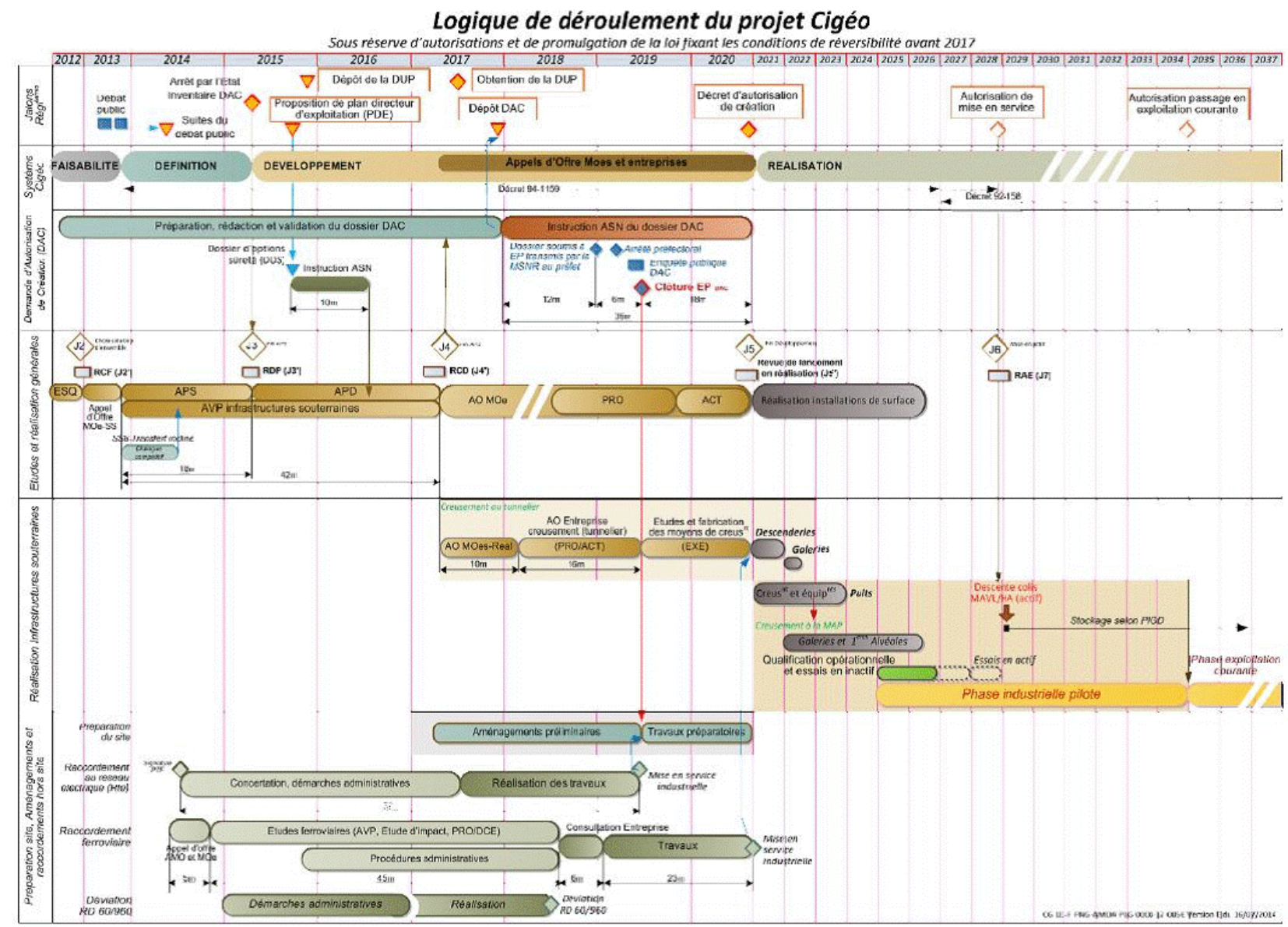

Fig. 2 Overall high-level schedule for the CIGÉO project, outdated version in French-for mere illustrative purpose CANDRA.

Several technical issues encountered during the design led the GAIYA consortium to evaluate and adapt different solutions proposed by the engineering subcontractors, presenting them to ANDRA and sometimes suggesting brand new ones.

Starting from the presentation of real examples of managing engineering issues, we will try in the following paragraphs to derive some lessons learned and point out some practices of interest that could be helpful in similar projects, with focus on their application to the engineering phase of deep geological repositories in different countries.

\subsection{The Project Organization}

During the preliminary design, the GAIYA consortium was selected by ANDRA, the project owner, for the engineering of the ensemble of the
CIGÉO facility systems. For the basic (and later detail) design phase, the whole CIGÉO system has been split in eight subsystems, of which the five main subsystems are designed by five separate consortia, which develop the original preliminary design delivered by GAIYA. The design of the "common utilities" subsystem is still under GAIYA's responsibility. The subdivision of the scope within subsystems is detailed in the following Table 1 and the organization chart in Fig. 3.

Subsystems 6 and 7, which are not managed by GAIYA and therefore not listed above, concern the future facility operations managed and the design of packages carried out by ANDRA itself.

As project owner, ANDRA is assisted by several organizations, for instance, it has granted contracts for ownership assistance for regulatory control and inspection and it is independently audited. 


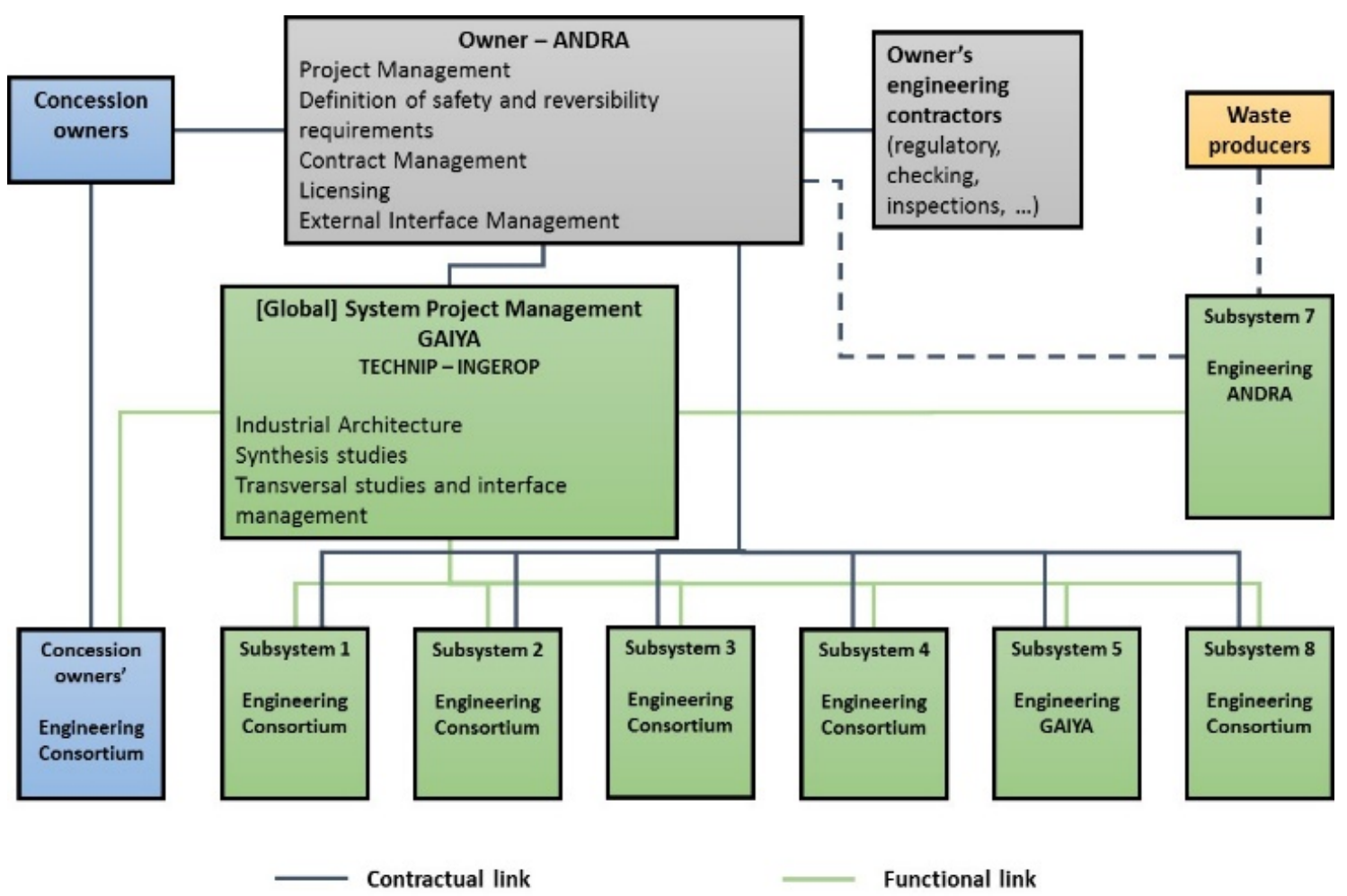

Fig. 3 Simplified organization chart for the project during the basic design phase.

Table 1 Detail of engineering work breakdown within subsystems.

\begin{tabular}{|c|c|c|c|c|c|c|}
\hline & Subsystem 1 & Subsystem 2 & Subsystem 3 & Subsystem 4 & Subsystem 5 & Subsystem 8 \\
\hline Definition & Nuclear process & $\begin{array}{l}\text { Surface facilities, } \\
\text { nuclear }\end{array}$ & $\begin{array}{l}\text { Surface facilities, } \\
\text { conventional }\end{array}$ & $\begin{array}{l}\text { Underground } \\
\text { facilities }\end{array}$ & $\begin{array}{l}\text { Common } \\
\text { utilities }\end{array}$ & $\begin{array}{l}\text { Cable railway } \\
\text { system (turnkey) }\end{array}$ \\
\hline $\begin{array}{l}\text { Scope } \\
\text { description (not } \\
\text { exhaustive) }\end{array}$ & $\begin{array}{l}\text { Control, flow } \\
\text { and transport } \\
\text { process for the } \\
\text { waste packages } \\
\text { along the whole } \\
\text { facility }\end{array}$ & $\begin{array}{l}\text { Nuclear } \\
\text { installations, } \\
\text { package reception } \\
\text { and conditioning } \\
\text { ventilation, } \\
\text { handling systems }\end{array}$ & $\begin{array}{l}\text { Conventional and } \\
\text { support facilities, } \\
\text { transport terminals, } \\
\text { logistics and offices }\end{array}$ & $\begin{array}{l}\text { All excavation and } \\
\text { construction works, } \\
\text { for tunnels, wells, } \\
\text { declines and } \\
\text { disposal cells, } \\
\text { including facilities } \\
\text { and logistic zones }\end{array}$ & $\begin{array}{l}\text { Platforms, } \\
\text { interfaces, } \\
\text { networks } \\
\text { between } \\
\text { subsystems }\end{array}$ & $\begin{array}{l}\text { System for } \\
\text { transporting the } \\
\text { waste packages } \\
\text { along the declines }\end{array}$ \\
\hline
\end{tabular}

The communication paths, concerning technical and organizational matters, have been arranged according to a strict pyramid scheme fashion. Each one of the five subsystem consortia manages its own internal communication between partners, addressing GAIYA only for matters which require an interaction with GAIYA itself, with ANDRA or with the other subsystems. GAIYA receives and transmits communications from and to ANDRA to the subsystem consortia. ANDRA exerts its control on GAIYA and the subsystem consortia, while assuring the communication with the other involved entities and stakeholders (owner's engineer, advisors, waste producers, external control and regulatory bodies, government and public).

As explained further on, in order to ease the solution of pending technical issues, recently "horizontal communication" has been allowed and encouraged between subsystem consortia, albeit under GAIYA's supervision.

GAIYA centralizes the document management including all the deliverables produced and exchanged by and within all subsystems and ANDRA, and manages as well the project's interfaces, changes and 
configurations. Dealing with these topics represents a huge workload, not only because of volumes, but most of all because of the relating technical aspects to be understood, mastered and taken into account in the coordination of the design activities, with the aim of attaining overall consistency and coherency in the design.

\subsection{Examples of Critical Technical Topics}

As already stated above, it is challenging to handle the complex and multidisciplinary technical subjects emerging in the design of CIGÉO, as they involve several competencies that are mainly clustered in two different worlds, having two different languages, professional backgrounds and methods: nuclear operations and mining. The dialogue between these two worlds is sometimes difficult, so a big effort to bring them together is required by project management, this is a situation that is likely to be found in other similar projects worldwide.

The layout studies have an important role in keeping track of the evolution of the design, so as to provide a continuous optimization and configuration management based on 3D models. Such models represent an easier detection tool for interface problems, a support for coherence reviews as well as a mean for testing the proposed schemes for waste package handling and streams management with respect to the demanded capacity goals.

The facility's architecture is indeed an industrial challenge: the site's productivity and reliability are crucial objectives, as uninterrupted fluxes and optimum process time at the storage facility will be key success factors (or could result in bottlenecks) of all the chain of decommissioning and dismantling for the French nuclear power plants fleet.

A general added difficulty to CIGÉO design is that, after the beginning of operations involving waste packages, scheduled in 2025, there will be the coexistence on the site of sectors under construction and in operation-even after the disposal of the first waste packages, thus introducing a potential radiological risk.

Managing such coactivity between operation and works asks for engineering solutions which are more complex and economically onerous, and for thorough questioning of design choices.

The basic, sound principle adopted to allow a seamless coexistence is to reduce the common structures as much as possible by means of partitioning, and making construction works, in particular excavation, dodge the zone where the operations are in progress.

Furthermore, even in this area of operations, there is the need for managing coactivity, as multiple activities will take in place in a very restricted space with a minimum use of human resources: arrival of new waste disposal packages, handling, controls, package introduction in - and potentially removal from - the dedicated disposal cells, maintenance, sealing of cells, etc. A tough nut to crack, from an engineering as well as from an organizational point of view.

The application of the best practices of industrial architecture, which is the core of the engineering know-how of INGEROP, helped GAIYA find the way out of some design deadlocks generated by the above mentioned challenges, and sometimes worsened by mono-objective visions focused on solving some specific (nuclear) engineering problem, while ignoring concurrent requirements, operational needs and the surrounding environment.

Last but not least, the CIGÉO facility's design is expected be flexible over time, so as to give the future generations the possibility to adapt the repository to new technologies and requirements, changes in waste policies (e.g., development of fast reactors, burning of actinides), and last but not least the feedback from operation and tests.

For instance, smaller pilot ILW disposal cells will be used to validate at first the concept, and only after about ten years the larger ones will be built integrating the return of experience by the tests. In order to cope 
with such flexibility in a reasonable way, the design should allow space for changes, variations and optimizations without an excessive impact on the costs: another source of complexity.

It would be impossible to write about every specific issue encountered so far along the studies, so let us focus on some interesting examples, and the (provisional or definitive) solutions chosen, if already found.

As regards the main topics connected with the geo-mechanics, physical properties and constraints due to the clay media, we want to mention the following ones:

- The clay rock behaviour over time and its implications-e.g., creep — on the zones surrounding the excavated tunnels. As the observation time for testing these phenomena is limited with respect to the lifetime of the facility (decades compared to centuries), modelling choices are critical and the uncertainties due to such extrapolation shall be taken into account;

- Integration of "dip" i.e., natural inclination of the clay layer (2\%) and its effect on the (anisotropic) mechanical efforts on the structures that have to be compensated. Such geological conformation has an impact on dimensioning tunnels and networks (e.g., on positioning water collectors);

- Influence of void fraction on the long-term behaviour of the disposal cells (extent of the zone affected by the long term cell liner collapse), and its link to the regulatory requirement for the minimum thickness of the upper and lower layers of unperturbed rock, i.e., $50 \mathrm{~m}$;

- Geometrical definition of the underground structures in a multi-constraint field, requiring interactive and trial and error methods, featuring a massive use of 3D modelling.

Several times the GAIYA consortium intervened directly in the discussion with ANDRA by promoting technical choices, concerning more general, industrial aspects of nuclear and/or mining facilities, in particular the ones listed below:

- A "full electric" approach for vehicles, construction and handling machines, and the use of cable railways for transport of waste packages along the declines - therefore excluding the use of thermic engine vehicles and reducing ignitable materials;

- A complete geographical and functional separation between the vertical wells for operation and construction (single function associated to each well) and with respect to the declines for waste transport from the surface to underground facilities. This choice led to larger capital expenditure but with reduced operational constraints and risks, the chosen solution features five wells (three dedicated to construction works, two to operations) and two declines;

- A bi-tube architecture concept for each access tunnel, a redundancy that allows for isolation and thus for the possibility of parallel operations in the same area, and improves fire protection, safety and security;

- A step-by-step implementation scheme for the disposal cells and sectors, with batch construction and testing of parts of each sector, leaving time for integrating the feedbacks from the tests in the design before the beginning of another new batch/excavation campaign - a solution that comes from the research of a tradeoff between investment cost and flexibility.

Forcing on the location of logistical support zones,

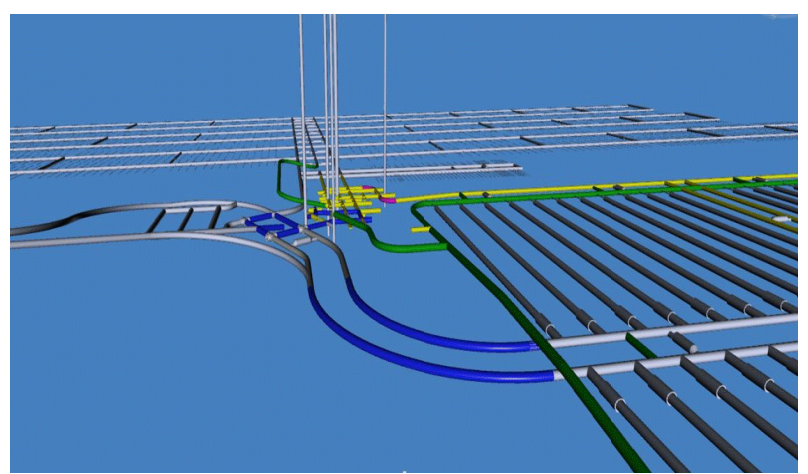

Fig. 4 3D view showing the connections at the "crossroad" of the underground structures, where wells, declines, logistical support zones and access galleries to the disposal cells converge (provisional design) @ANDRA. 
impact on the position of the vertical access wells, these zones are created as support and pivot for all underground activities: their arrangement has a direct which itself interact with the organization of the surface installations (Fig. 4). As long as the arrangement of the logistical support zones is not defined, the design studies of the surface installations surrounding the wells cannot be performed. This impasse has been overcome by imposing a geographical area for implantation on the site of each subsystem, based on a sub-optimal, intermediate hypothesis in order to resume and foster the progress of the concerned activities.

\subsection{Critical Organizational Topics}

As already done for technical topics, in this paragraph, we will mention some management issues and the way they will need to be addressed in the future, before and during the next steps, starting from the basic design phase. The project team and GAIYA solved —or are trying to solve - many of these issues, proposing sometimes more drastic/innovative solutions affecting the management culture.

Firstly, it is important to consider that, many companies, from various geographical locations (in France and abroad), having different backgrounds, approaches and organizational cultures are involved in the engineering studies: thus a constant guidance of the interactions between the parties and "multicultural" management have clearly a key role.

Secondly, the project planning is defined by the French government and enacted into law, so it is rigid and turns out to be very challenging. E.g., strict approaches in the procedures for reviewing and approving the project deliverables have proven to be a not-so-viable solution when respecting draconian deadlines becomes a priority.

Moreover, systemic inertia and delays in the decision making due to the organization's complexity led periodically to stand-by periods followed by rushes depending on the approval progress of certain subjects of the design: this meant a highly variable load (and a source of uneasiness) for the engineering teams.

In order to prevent these kind of hindrances, and get to a simpler, faster and more fluid progress of the studies, for the current final stage of the basic design and for the launching of the detail design, some remedial actions measures have been decided:

- To rethink completely the logic and the sequence of the studies, making use of a 6-months exhaustive schedule taking into account more accurately the interdependence of activities, decisions, inputs from the project owner and regulatory constraints;

- To share and communicate more with all the parties about the issues and the progress status;

- To intensify the interactions within GAIYA and the subsystem consortia, so as to combine the efforts and tackle jointly the issues still to be resolved, discussing more directly and taking advantage of the change of perspective.

\section{Results of Management Actions So Far}

\subsection{Feedbacks and Avenues for Reflections}

The optimization of the management process and structure is a work in progress, nevertheless a number of actions have being taken to improve the organization model.

For instance, following various seminars involving all the actors of the project, several items for which there is still room for improvement have been highlighted during the discussion, and action plans have been drawn. Here below some of the improvements identified as necessary are listed:

- Simplification, rationalization, alignment and consolidation of the project requirements must be carried out - as problems arise from the superposition and "stratification" of thousands of exigencies, which imply time to trace back their origin, evolution/history, purpose, validity, mutual compatibility and priority. Requirements shall be (re)defined according to the 
S.M.A.R.T. (specific, measurable, assignable, realistic and time-related) goals philosophy;

- More effective management of layout and integration studies, as well as coherency;

- Decision making to be focused on reduced and independent extents to accelerate the process;

- Interface management to be enhanced, as it is crucial to prevent and/or solve even layout problems, clashes, incongruences.

\subsection{From Settling Interface Conflicts to a Collaborative Working Approach}

Multiple interfaces were well mastered during the preliminary studies carried out by the GAIYA consortium, but an "explosion" in the number of interfaces occurred at the basic design stage, because of the work split into parallel studies of separate subsystems.

During the takeover of GAIYA's design activities by the engineering consortia working on the different subsystems, a long phase of know-how transfer has taken place on a specific, sector-wise basis.

This know-how transfer being effective, the project has now entered a second phase where a more transversal approach, breaking the compartmentalization of the studies is needed for the good of the project, so that, recently a new methodology of collaborative working meetings has been launched, involving multidisciplinary teams of all concerned subsystems to work on delicate topics, defusing them one by one. These meetings allow better understanding and visibility for the staff that worked for months only on their subsystem, improving their (and all staff's) experience, knowledge and problem solving capabilities.

As a matter of fact, the collaborative approach leads to a win/win situation and, in a contractual framework, such as the one dictated by ANDRA's public entity status, it is more effective than solving issues via a series of claim/counterclaim disputes between the parties.

\section{Conclusions}

We would like to summarize in this last paragraph, some lessons learned so far. Some are applicable to megaprojects in general, others concern only topics that are likely to be found also in other deep geological disposal projects around the world, whether in clay, granite or salt dome formations:

- A robust requirement management in complex and ever-changing environments is fundamental from $\mathrm{T} 0$, and it remains a key factor for preventing issues all along the project duration;

- Government, public and stakeholders are highly sensitive and prone to generate delay or put the pressure on the design activity as well, so one has to take this risk into account while defining the overall and detailed project schedule;

- It is important for the project team to question itself regularly, and stress-test even well working practices and known schemes when approaching new project phases (e.g., when switching from preliminary to basic design);

- Interface management and resolution by a collaborative approach can be more effective and less troublesome than arbitrating continuous conflicts and claims between different contractors;

- Many competences are scarce in this field, experienced people are a rare resource, and it is difficult to make experts coming mainly from underground works/mining and nuclear worlds talk the same "language", but it is necessary to make them work together closely and find a common ground (e.g., starting from safety goals);

- Multi-scale interface management and layout definition for a variety of systems and activities ask for a huge amount of dedicated resources to assure convergence and coherency of the design;

- When operations and construction works take place in a very restricted underground space with high level of coactivity, harsh operating constraints and considerable risks to be managed (fire, radiological, insufficient air flow, etc.), every single detail in the 
design phase becomes critical.

\section{Acknowledgments}

My thanks go out to:

- ANDRA's staff for the trust they place in INGEROP year after year;

- TECHNIP's staff for the good cooperation within the GAIYA consortium;

- Ms. François Laupretre, CIGÉO project technical director-GAIYA consortium;
- The whole INGEROP's CIGÉO project team.

\section{References}

[1] ANDRA-CIGEO Project English Website: http://www.andra.fr/international/.

[2] ASN (French Nuclear Safety Authority). 2008. "Guide de Sûreté Relative au Stockage Définitive des Déchets Radioactifs en Formation Géologique Profonde.” ASN.

[3] Labalette, A., Harman, M. C. D., and Ouzounian, G. 2013. "CIGÉO, the French Geological Repository Project-13022." Presented at the WM2013 Conference, Phoenix, Arizona, USA. 